\title{
ANALISIS PENERIMAAN APLIKASI SISKEUDES DI LINGKUNGAN PEMERINTAH DAERAH KABUPATEN SAMBAS
}

\author{
Eko Febri Lusiono ${ }^{1}$ \\ Suharman ${ }^{2}$ \\ Prodi Akuntansi Keuangan Perusahaan \\ Politeknik Negeri Sambas \\ Email: ekodelisa2004@gmail.com
}

\begin{abstract}
ABSTRAK
Penelitian Analisis Penerimaan Aplikasi SISKEUDES di Lingkungan Pemerintah Daerah Kabupaten Sambas adalah untuk mengetahui sejauh mana penerimaan aplikasi SISKUEDES di kabupaten Sambas. Jumlah responden adalah 50 aparatur desa dari sepuluh kecamatan di kabupaten Sambas. Kecamatan tersebut adalah kecamatan Selakau, Selakau Timur, Salatiga, Pemangkat, Semparuk, Tebas, Sebawi, Sambas, Sejangkung, Sajad dan Subah. Penelitian ini dilakukan dengan menggunakan Teori Acceptance Model (TAM) dengan tujuh konstruksi murni (tujuh hipotesis). Actual Use (AU) sebagai variabel dependen, sedangkan perceived ease of use (PEOU), perceived usefulness (PU), attitude (ATT), behavioral intention (BI) sebagai variabel independen. Berdasarkan analisis regresi berganda dengan aplikasi SPSS 17 dapat dilihat bahwa H1, H2, H3, dan H5 diterima karena nilai signifikansi pada tabel Anova lebih kecil dari 0,05. Sementara H4, H6, dan H7 ditolak. Berdasarkan hal tersebut dapat disimpulkan bahwa perceived usefulness dan perceived ease of use menjadi tolak ukur aparatur desa untuk menerima suatu aplikasi.
\end{abstract}

Kata Kunci: Model Penerimaan Teori (TAM), SISKEUDES

\begin{abstract}
The Research of SISKEUDES Application Acceptance Analysis in local government environment of Sambas district is to know the extent of acceptance of SISKUEDES application in Sambas district. Total respondents were 50 village apparatus from ten districts in Sambas district. The sub-districts are Selakau, Selakau Timur, Salatiga, Pemangkat, Semparuk, Tebas, Sebawi, Sambas, Sejangkung, Sajad and Subah sub-districts. The study was conducted using Theory Acceptance Model (TAM) with seven pure constructs (seven hypotheses). Actual Use $(A U)$ as the dependent variable, while perceived ease of use (PEOU), perceived usefulness (PU), attitude (ATT), behavioral intention (BI) as independent variables. Based on multiple regresilinear regression analysis with SPSS 17 application it can be seen that $\mathrm{H1}, \mathrm{H2}, \mathrm{H3}$, and $\mathrm{H5}$ are accepted because the significance value in Anova table is smaller than 0.05 . While $\mathrm{H} 4, \mathrm{H} 6$, and $\mathrm{H} 7$ rejected.

Based on this it can be concluded that perceived usefulness perceptions and perceived ease of use perceptions become the benchmark of rural apparatus to accept an application.
\end{abstract}

Keyword: Theory Acceptance Model (TAM), SISKEUDES.

\section{PENDAHULUAN}

Kemajuan teknologi informasi yang pesat dengan potensi pemanfaatan yang sangat luas, menyediakan peluang bagi pengaksesan, pengelolaan, dan penggunaan teknologi informasi dalam jumlah yang sangat besar. Hal ini menunjukan bahwa penggunaan sistem teknologi informasi khususnya media elektronik dan aplikasi berbasis web merupakan hal yang sangat penting dalam berbagai transaksi nasional maupun internasional, khususnya dalam transaksi keuangan.

Ketidakmampuan menyesuaikan diri dengan kecenderungan global tersebut membawa negara ke dalam jurang digital divide, yaitu keterisolasian 
dari perkembangan global akibat ketidakmampuan dalam memanfaatkan sistem informasi.

Pemerintah Indonesia melalui Instruksi Presiden Republik Indonesia Nomor 3 Tahun 2003 Tentang Kebijakan dan Strategi Nasional Pengembangan E-Goverment melaksanakan proses transformasi menuju e-government. Dilingkungan Kementerian Keuangan untuk mewujudkan $e$ government dan tercapainya profesionalitas serta kualitas pengelolaan keuangan negara, maka pemerintah melaksanakan sebuah proyek untuk penyempurnaan manajemen keuangan dan administrasi penerimaan pemerintah yang disebut dengan Government Financial Management and Revenue Administration Project (GFMRAP). GFMRAP meliputi 4 bidang, yaitu manajemen keuangan publik administrasi pendapatan, tata kelola dan akuntabilitas, dan tata kelola proyek dan implementasi.

Manajemen keuangan publik atau pengelolaan keuangan pemerintah harus dimulai dari tatanan pemerintahan yang paling bawah yaitu pemerintahan desa. Mengingat pada saat ini pemerintah desa sudah mengelola sejumlah kas negara dengan jumlah yang cukup besar, untuk mendukung kegiatan tersebut pemerintah khususnya pihak BPKP membuat sebuah aplikasi yang bertujuan untuk meningkatkan kualitas tata kelola keungan desa. Aplikasi yang dimaksud adalaha Aplikasi Sistem Keuangan Desa (SISKEUDES).

Pengembangan aplikasi SISKEUDES sudah dipersiapkan sejak awal dalam rangka mengantisipasi penerapan UU Nomor 6 Tahun 2014 tentang Desa. Persiapan ini selaras dengan adanya perhatian yang lebih dari komisi IX DPR RI maupun KPK. Launching aplikasi SISKEUDES pada tanggal 13 Juli 2015 merupakan jawaban atas pertanyaan pada rapat dengar pendapat (RDP) komisi IX tanggal 30 Maret 2015, yang menanyakan kepastian waktu penyelesaian aplikasi yang dibuat oleh BPKP, serta memenuhi rekomendasi KPK-RI untuk menyusun sistem keuangan desa bersama dengan kementerian dalam negeri.

Aplikasi SISKEUDES merupakan aplikasi yang dibuat sederhana dan mudah digunakan sehingga memudahkan pengguna untuk mengoperasikannya. Dengan satu kali proses penginputan sesuai dengan transaksi yang ada, dapat menghasilkan output berupa dokumen penatausahaan dan laporan laporan yang sesuai dengan ketentuan peraturan perundang - undangan yang berlaku, dengan demikian Aplikasi SISKEUDES ini sangat membantu aparatur pemerintah desa dalam mengelola keuangan desa.

Aparatur desa di seluruh Indonesia yang mempunyai tugas mengelola keuangan desa seharusnya sudah menggunakan aplikasi SISKEUDES yang dapat membantu pelaksanaan tugas tersebut mengingat aplikasi tersebut sudah diluncurkan pada tahun 2015 .
Penelitian terdahulu yang berkaitan dengan penerimaan sebuah teknologi informasi, satunya adalah penelitian yang berjudul analisis penerimaan Mobile Banking (M-Banking) dengan pengalaman (experience) sebagai variabel eksternal dengan menggunakan pendekatan technology acceptance model (TAM) oleh Loggar Bhilawa pada tahun 2010. Penelitian ini bertujuan untuk mengetahui pengalaman (experience) terhadap penerimaan teknologi informasi yaitu dalam penggunaan aplikasi mobile banking dengan kerangka model technology acceptance model (TAM). Sampel dari penelitian ini adalah nasabah bank - bank yang mengaplikasikan layanan mobile banking, sedangkan analisis yang digunakan adalah analisis path.

Berdasarkan uraian diatas, peneliti tertarik untuk melakukan penelitian terkait dengan penerimaan teknologi informasi yang berjudul "Analisis penerimaan Aplikasi SISKEUDES di Pemerintah Daerah Kabupaten Sambas".

\section{TELAAH LITERATUR}

\subsection{Desa dan Pemerintahan Desa}

Menurut Permendagri Nomor 113 Tahun 2014, diungkapkan bahwa desa dan desa adat atau yang disebut dengan nama lain, selanjutnya disebut Desa, adalah kesatuan masyarakat hukum yang memiliki batas wilayah yang berwenang untuk mengatur dan mengurus urusan pemerintahan, kepentingan masyarakat setempat berdasarkan prakarsa masyarakat, hak asal usul, dan/atau hak tradisional yang diakui dan dihormati dalam sistem pemerintahan Negara Republik Indonesia.

Desa dalam pengertian umum adalah sebagai suatu gejala yang bersifat universal, terdapat dimana pun di dunia ini, sebagai suatu komunitas kecil, yang terikat pada lokalitas tertentu baik sebagai tempat tinggal (secara menetap) maupun bagi pemenuhan kebutuhannya, dan terutama yang tergantung pada sektor pertanian (Edi Indirizal, 2006).

Pemerintahan Desa menurut Permendagri Nomor 113 tahun 2014 adalah penyelenggaraan urusan pemerintahan dan kepentingan masyarakat setempat dalam sistem pemerintahan NKRI. Pemerintah Desa adalah kepala desa atau sebutan lainnya dibantu perangkat desa sebagai unsur peyelenggara pemerintah desa.

\subsection{Pengelolaan Keuangan desa}

Menurut permendagri Nomor 113 tahun 2014, Keuangan Desa adalah semua hak dan kewajiban desa yang dapat dinilai dengan uang serta segala sesuatu berupa uang dan barang yang berhubungan dengan pelaksanaan hak dan kewajiban desa.

Menurut permendagri Nomor 113 Tahun 2014, Pengelolaan Keuangan Desa adalah keseluruhan kegiatan yang meliputi perencanaan, pelaksanaan, penatausahaan, pelaporan, dan pertanggungjawaban keuangan desa. 


\section{a. Perencanaan}

Pemerintah desa menyusun perencanaan pembangunan desa sesuai dengan kewenangannya dengan mengacu pada perencanaan pembangunan kabupaten/kota. Rencana pembangunan desa disusun untuk menjamin keterkaitan dan konsistensi antara perencanaan, pelaksanaan, dan pengawasan.

\section{b. Pelaksanaan}

Dalam pelaksanaan anggaran desa yang sudah ditetapkan sebelumnya timbul transaksi penerimaan dan pengeluaran desa. Semua penerimaan dan pengeluaran desa dalam rangka pelaksanaan kewenagan desa dilaksanakan melalui rekening kas desa. Jika desa yang belum memiliki pelayanan perbankan diwilayahnya maka pengaturannya ditetapkan oleh pemerintah kabupaten/kota serta semua penerimaan dan pengeluaran desa harus didukung oleh bukti yang lengkap dan sah.

\section{c. Penatausahaan}

Kepala desa dalam melakukan penatausahaan keuangan desa harus menetapkan bendahara desa. Penetapan bendahara desa harus dilakukan sebelum dimulainya tahun anggaran bersangkutan dan berdasarkan keputusan kepala desa. Bendahara adalah perangkat desa yang ditunjuk oleh kepala desa untuk menerima, menyimpan, menyetorkan, menatausahakan, membayar, dan mempertanggungjawabkan keuangan desa dalam rangka pelaksanaan APBDes.

Bendahara desa wajib mempertanggungjawabkan keuangan desa dalam sebuah laporan. Laporan pertanggungjawaban yang dibuat oleh bendahara desa adalah:
a. Buku Kas Umum
b. Buku Kas Pembantu Pajak
c. Buku Bank

\section{d. Pelaporan}

Menurut Permendagri Nomor 113 Tahun 2014 dan Ardi Hamzah (2015) dalam melaksanakan tugas, kewenangan, hak, dan kewajiban, kepala desa wajib:

a. Menyampaikan laporan realisasi pelaksanaan APBDesa kepada Bupati/Walikota

b. Menyampaikan LPPD setiap akhir tahun anggaran kepada bupati/walikota

c. Menyampaikan LPPD pada akhir masa jabatan bupati/walikota

d. Memyampaikan laporan keterangan peyelenggaraan pemerintah desa secara tertulis kepada BPD setiap akhir tahun anggaran.

\subsection{Aplikasi Sistem Keuangan Desa (Siskeudes)}

Aplikasi Sistem Keuangan Desa (SISKEUDES) merupakan aplikasi yang dikembangkan Badan Pengawasan Keuangan dan Pembangunan (BPKP) dalam rangka meningkatkan kualitas tata kelola keuangan desa. Fitur-fitur yang ada dalam Aplikasi Pengelolaan Keuangan Desa dibuat sederhana dan userfriendly sehingga memudahkan pengguna dalam mengoperasikan aplikasi SISKEUDES.

Dengan proses penginputan sekali sesuai dengan transaksi yang ada, dapat menghasilkan output berupa dokumen penatausahaan dan laporanlaporan yang sesuai dengan ketentuan perundangundangan, antara lain:

a. Dokumen Penatausahaan

b. Bukti Penerimaan;

c. Surat Permintaan Pembayaran (SPP);

d. Surat Setoran Pajak (SSP)

e. Dan dokumen-dokumen lainnya

f. Laporan-laporan:

g. Laporan Penganggaran (Perdes APB Desa, RAB, APB Desa per sumber dana);

h. Laporan Penatausahaan (Buku Kas Umum, Buku Bank, Buku Pajak, Buku Pembantu, dan Register

\subsection{Technology Acceptance Model (TAM)}

Penelitian ini menggunakan konsep Technology Accaptance Model (TAM) atau yang lebih dikenal dengan Model Penerimaan Teknologi. Teori ini pertama kali dikenalkan oleh Davis (1986) dalam Jogiyanto (2007). Davis mendefinisikan bahwa TAM merupakan suatu model penerimaan sistem teknologi informasi yang akan digunakan oleh pemakai. TAM berargumentasi bahwa penerima individual terhadap sistem teknologi informasi ditentukan oleh dua konstruk yaitu: kegunaan persepsian (perceived usefulness) dan kemudahan penggunaan persepsian (perceived ease of use).

Kegunaan persepsian (perceived usefulness) dan kemudahan penggunaan persepsian (perceived ease of use) keduanya mempunyai pengaruh ke minat perilaku (behavioral intention). Pemakai teknologi akan mempunyai minat menggunakan teknologi (minat perilaku) jika sistem teknologi bermanfaat dan mudah digunakan. Sedangkan kegunaan persepsian (perceived usefulness) juga mempengaruhi kemudahan penggunaan persepsian (perceived ease of use) tetapi tidak sebaliknya. Pemakai sistem akan menggunakan sistem jika sistem itu bermanfaat mudah digunakan atau tidak mudah digunakan. Sistem yang sulit digunakan akan tetap digunakan jika pemakai merasa bahwa sistem masih berguna. Model dari TAM terlihat pada Gambar 1.1 dibawah ini: 


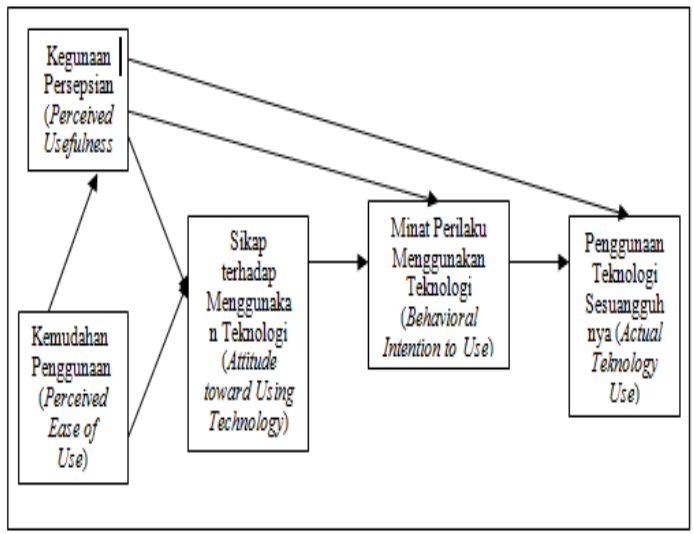

Gambar. 1.1.

Technology Acceptance Model (TAM)

\subsection{Hipotesis Penelitian}

Berdasarkan kerangka pemikiran di atas, hipotesis penelitian tampak pada Gambar 1.2 dibawah ini:

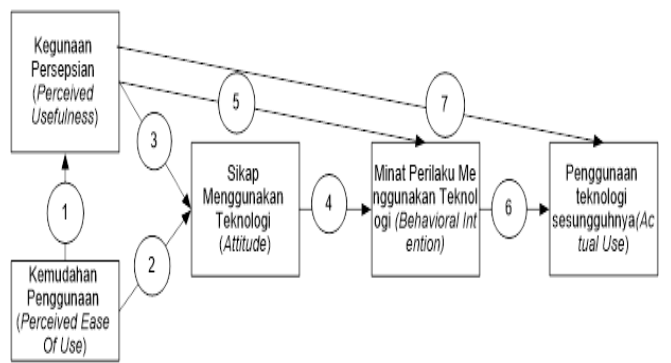

Gambar 1.2

Hipotesis Penelitian

\section{METODE PENELITIAN}

\subsection{Objek dan Bentuk Penelitian}

Objek penelitian merupakan sasaran, tujuan, dan kegunaan terhadap sesuatu permasalahan untuk mendapatkan jawaban atau solusi dan kemudian dapat ditarik sebuah kesimpulan. Objek dalam penelitian ini adalah aparatur pemerintah desa yang mempunyai tugas dan tanggung jawab sebagai pengelola keuangan desa di pemerintah daerah kabupaten Sambas. Sedangkan bentuk penelitian yang digunakan dalam penelitian ini adalah penelitian explanatory yang bertujuan untuk mengetahui hubungan kausalitas antar variabel melalui suatu pengujian hipotesis (Jogiyanto, 2007:54).

\subsection{Jenis dan Sumber Data}

Pada penelitian ini peneliti menggunakan data primer dan data sekunder. Data primer adalah data yang dikumpulkan langsung dari sumber data dan berhubungan langsung dengan permasalahan yang diteliti (Kuncoro, 2009:148), dalam penelitian ini data primernya berupa data yang diperoleh dari responden melalui kuesioner. Sedangkan data sekunder adalah data yang diperoleh dari pihak lain, tidak langsung diperoleh peneliti dari subjek penelitiannya, dalam penelitian ini data sekundernya berupa studi pustaka (buku, jurnal dll).

\subsection{Operasionalisasi Variabel}

\subsubsection{Variabel Dependen}

Kuncoro (2009) mendefinisikan bahwa variabel dependen adalah variabel yang menjadi perhatian utama dalam sebuah pengamatan. Variable dependen pada penelitian ini adalah penggunaan teknologi sesungguhnya (actual technology use).

Jogiyanto (2007) menyebutkan bahwa perilaku (behavior) adalah tindakan yang dilakukan oleh seseorang. Dalam konteks sistem teknologi informasi, perilaku (behavior) adalah penggunaan sesungguhnya (actual use) dari teknologi. Jadi kesimpulannya adalah penggunaan teknologi sesungguhnya (actual technology use) merupakan tindakan yang dilakukan secara langsung oleh seseorang terhadap teknologi.

1. Kegunaan persepsian (Perceived usefulness)

Jogiyanto (2007:114) mendefinisikan bahwa: "Kegunaan persepsian (perceived usefulness) adalah sejauh mana seseorang mempercayai bahwa menggunakan teknologi akan meningkatkan kinerjanya". Dari definisi tersebut dapat disimpulkan bahwa kegunaan persepsian (perceived usefulness) adalah suatu kepercayaan (belief) tentang proses pengambilan keputusan.

2. Kemudahan Penggunaan Persepsian (Perceived Ease of Use)

Kemudahan penggunaan persepsian (perceived ease of use) didefinisikan sebagai sejauh mana seseorang percaya bahwa menggunakan teknologi akan bebas dari usaha. Dari definisi tersebut, diketahui bahwa konstruk kemudahan persepsian (perceived ease of use) merupakan suatu kepercayaan tentang suatu proses pengambilan keputusan (Jogiyanto, 2007:115).

3. Sikap Terhadap Menggunakan Teknologi (Attitude Toward Using Technology)

Davis et al (1989) mendefinisikan sikap terhadap perilaku (attitude toward behavior) sebagai "perasaan positif atau negatif dari seseorang jika harus melakukan perilaku yang akan ditentukan". Mathieson (1991) dalam Jogiyanto (2007:116) mendefinisikan sikap terhadap perilaku sebagai evaluasi pemakai tentang ketertarikan menggunakan sistem. Berdasarkan pengertian di atas dapat disimpulkan bahwa sikap terhadap menggunakan teknologi (attitude toward using technology) adalah perasaan seseorang saat menggunakan teknologi.

4. Minat Perilaku Menggunakan Teknologi (Behavioral Intention To Use)

Jogiyanto (2007:117) mendefinisikan minat perilaku (behavioral intention) adalah" suatu keinginan seseorang untuk melakukan suatu perilaku tertentu". Jadi minat perilaku menggunakan teknologi (behavioral intention to use) adalah suatu keinginan seseorang untuk menggunakan teknologi. 


\subsubsection{Variabel Interving}

Kuncoro (2009) mendefinisikan bahwa "variabel intervening adalah faktor yang berpengaruh pada fenomena yang diamati tetapi tidak dapat dilihat, diukur, atau dimanipulasi, namun dampaknya dapat disimpulkan berdasarkan dampak variabel independen dan moderating terhadap fenomena yang diamati”.

\subsection{Teknik Pengumpulan Data}

Sugiyono (2012) mendefinisikan bahwa "kuesioner adalah teknik pengumpulan data yang dilakukan dengan cara memberi seperangkat pertanyaan atau pernyataan tertulis kepada responden untuk dijawabnya". Penyebaran kuesioner menggunakan teknik sampling, dimana peneliti menyebar 50 (lima puluh) lembar kueisoner di sepuluh kecamatan di kabupaten sambas. Peneliti menggunakan 10 (sepuluh) kuesioner sebagai media untuk menguji apakah kuesioner layak digunakan atau tidak. Pada penelitian ini peneliti juga menggunakan berbagai karya tulis, buku, dan jurnal sebagai media untuk memperoleh informasi yang akan mendukung penelitian, dan media-media tersebut akan dicantumkan pada daftar pustaka.

\subsection{Teknik Analisis Data}

Teknik analisis yang digunakan dalam penelitian ini adalah teknik analisis regresi berganda dan analisis path dengan menggunakan program Statistik SPSS 17. Sedangkan skala pengukuran yang digunakan adalah sebagai berikut:

\subsubsection{Uji Validitas}

Suatu skala pengukuran dikatakan valid apabila melakukan yang seharusnya diukur. Bila skala pengukuran tidak valid maka tidak bermanfaat bagi peneliti karena tidak mengukur atau melakukan apa yang seharusnya dilakukan (Kuncoro, 2009:172). Pada penelitian ini data dinyatakan valid jika nilai $r_{\text {hitung }}>r_{\text {tabel }}$ dengan signifikansi $5 \%$.

\subsubsection{Uji Reliabilitas}

Reliabilitas menunjukkan konsistensi dan stabilitas dari suatu faktor (skala pengukuran). Reliabilitas berbeda dengan validitas karena yang pertama memusatkan perhatian pada masalah konsistensi, sedangkan yang kedua lebih memperhatikan masalah ketepatan. Dengan demikian, reliabilitas mencakup dua hal utama, yaitu: stabilitas ukuran dan konsistensi internal ukuran (Sekaran, 2000) dalam Kuncoro, (2009:175). Pada penelitian ini konstruk dinyatakan reliabel jika nilai cronbach alpha di atas 0,70 .

\subsubsection{Uji Asumsi Klasik}

Menurut Budianas (2013) uji asumsi klasik adalah persyaratan statistik yang harus dipenuhi pada analisis regresi linear berganda. Menurut Setyadharma (2010) sedikitnya terdapat lima uji asumsi yang harus dilakukan terhadap suatu model regresi tersebut yaitu: uji normalitas, uji autokolerasi, uji multikolinieritas, uji heteroskedastitas, dan uji linearitas. Namun tidak semua uji harus dilakukan, seorang peneliti harus bisa menentukan uji apa yang harus dilakukan pada penelitiaannya.

Pada penelitian ini uji asumsi yang dilakukan penulis adalah uji normalitas. Menurut Budianas (2013) uji normalitas adalah untuk melihat apakah nilai residual terdistribusi normal atau tidak. Model regresi yang baik yaitu memiliki nilai residual yang berdistribusi normal. Pada penelitian ini penulis melakukan uji normalitas dengan cara uji histogram dan uji normal P Plot atau dengan cara melihat grafik pada hasil olah data uji normalitas dengan SPSS.

\subsubsection{Analisis Regresi Linear Berganda}

Analisis regresi linear berganda adalah analisis yang digunakan untuk mengukur pengaruh antara lebih dari satu variabel (Kuncoro, 2009:236). Rumus analisis regresi/persamaan umum regresi dalam penelitian ini adalah sebagai berikut:

$$
\begin{array}{ll}
\text { Y=a }+b_{1} X_{1}+b_{2} X_{2}+\ldots \ldots b_{n} X_{n} \\
\text { PU } \quad=a_{1}+b_{1} \text { PEOU } \\
\text { ATT } \quad=a_{2}+b_{2} \text { PU }+b_{3} \text { PEOU } \\
\text { BI } \quad=a_{3}+b_{4} \text { ATT }+b_{5} \text { PU } \\
\text { AU } \quad=a_{5}+b_{6} \text { BI+ } b_{7} \text { PU } \\
\text { Keterangan } \\
\text { Y } \quad=\text { Konstanta } \\
\text { PU } \quad=\text { Perceived Usefulness/PU } \\
\text { PEOU }=\text { Perceived ease of use/PEOU } \\
\text { ATT }=\text { Attitude } \\
\text { BI }=\text { Behavioral Intention } \\
\text { AU }=\text { Actual Use } \\
a_{1 \ldots 5}=\text { Konstanta } \\
\mathrm{b}_{1 \ldots 9}=\text { Koef Regresi }
\end{array}
$$

\section{HASIL PENELITIAN DAN \\ PEMBAHASAN}

\subsection{Hasil Uji Kuesioner}

Sebelum kuesioner disebarkan kepada sampel (responden) sebenarnya, dilakukan pilot testing atau uji kuesioner terlebih dahulu yaitu menguji kuesioner terhadap 15 orang aparatur pemerintah desa yang telah menggunakan aplikasi SISKEUDES. Pilot Testing dilakukan dengan menguji tingkat validitas dan reliabilitas data. Hasil pengujian validitas dan reliabilitas pada pilot testing terlihat pada tabel berikut ini: 
Tabel. 1.2

Tabel 1.1

Hasil Pengumpulan Data

Uji Validitas Kuesioner

\begin{tabular}{|c|c|c|c|c|}
\hline No & Pernyataan & $\begin{array}{l}\text { Nilai } \\
\text { rhitung }\end{array}$ & $\begin{array}{c}\text { Nilai } \\
\text { rtabel }\end{array}$ & $\begin{array}{c}\text { Validit } \\
\text { as }\end{array}$ \\
\hline 1 & PU1 & 0.878 & 0,514 & Valid \\
\hline 2 & PU2 & 0,836 & 0,514 & Valid \\
\hline 3 & PU3 & 0,769 & 0,514 & Valid \\
\hline 4 & PU4 & 0,689 & 0,514 & Valid \\
\hline 5 & PU5 & 0,522 & 0,514 & Valid \\
\hline 6 & PEOU1 & 0,572 & 0,514 & Valid \\
\hline 7 & PEOU2 & 0,736 & 0,514 & Valid \\
\hline 8 & PEOU3 & 0,619 & 0,514 & Valid \\
\hline 9 & PEOU4 & 0,747 & 0,514 & Valid \\
\hline 10 & PEOU5 & 0,723 & 0,514 & Valid \\
\hline 11 & PEOU6 & 0,723 & 0,514 & Valid \\
\hline 12 & ATT1 & 0,805 & 0,514 & Valid \\
\hline 13 & ATT2 & 0,805 & 0,514 & Valid \\
\hline 14 & ATT3 & 0,793 & 0,514 & Valid \\
\hline 15 & ATT4 & 0,166 & 0,514 & $\begin{array}{l}\text { Tidak } \\
\text { Valid }\end{array}$ \\
\hline 16 & BI1 & 0,836 & 0,514 & Valid \\
\hline 17 & $\mathrm{BI} 2$ & 0,884 & 0,514 & Valid \\
\hline 18 & BI3 & 0,527 & 0,514 & Valid \\
\hline 19 & BI4 & 0,724 & 0,514 & Valid \\
\hline 20 & AU1 & 0,422 & 0,514 & $\begin{array}{l}\text { Tidak } \\
\text { Valid }\end{array}$ \\
\hline 21 & AU2 & 0,526 & 0,514 & Valid \\
\hline
\end{tabular}

Hasil dari uji validas kuesioner tersebut menyebutkan bahwa dari 21 butir pentanyaan, ada dua pertanyaan yg tidak valid, sehingga kedua pertanyaan tersebut dibuang.

Penelitian yang dilakukan penulis menggunakan data dan informasi yang diperoleh dari hasil penyebaran kuesioner yang disebar kepada pengelola keuangan desa di sepuluh kecamatan. Kecamatan tersebut antara lain adalah sebagai berikut:
1. Kecamatan Selakau
2. Kecamatan Selakau Timur
3. Kecamatan Salatiga
4. Kecamatan Pemangkat
5. Kecamatan Semparuk
6. Kecamatan Tebas
7. Kecamatan Sebawi
8. Kecamatan Sambas
9. Kecamatan Sejangkung
10. Kecamatan Subah

\subsection{Deskriptif Responden}

Metode pengambilan sampel dalam penelitian ini dilakukan dengan cara purposive judgment sampling, yaitu pengambilan sampel dari suatu populasi dengan pertimbangan kriteria tertentu (Jogiyanto, 2012). Dalam penelitian ini kriteria responden tersebut adalah mereka yang mengenal aplikasi Siskeudes dan merupakan aparatur pemerintahan desa. Hasil dari pengumpulan data berupa kuesioner yang dikembalikan dan memenuhi syarat adalah sebagai berikut:

\begin{tabular}{|c|l|c|c|}
\hline No & \multicolumn{1}{|c|}{ Keterangan } & Jumlah & Presentase \\
\hline 1 & $\begin{array}{l}\text { Kuesioner yang } \\
\text { disebar }\end{array}$ & 50 & $100 \%$ \\
\hline 2 & $\begin{array}{l}\text { Kuesioner } \\
\text { kembali }\end{array}$ & 50 & $100 \%$ \\
\hline 3 & $\begin{array}{l}\text { Kuesioner yang } \\
\text { rusak }\end{array}$ & 10 & $20 \%$ \\
\hline $\begin{array}{l}\text { Jumlah Kuesioner yang } \\
\text { diolah }\end{array}$ & 40 & $80 \%$ \\
\hline
\end{tabular}

Berdasarkan hasil penyebaran kuesioner yang berjumlah 50 lembar diketahui bahwa $100 \%$ kuesioner atau 50 lembar kuesioner kembali. Kuesioner yang rusak dikarenakan jawaban tidak lengkap sebanyak 20\% atau sebanyak 10 lembar, sehingga kuesioner yang bisa diolah sebanyak $80 \%$ atau sebayak 40 lembar.

\subsection{Karakteristik Responden}

Analisis deskriptif responden dalam penelitian ini digunakan untuk mengetahui distribusi responden berdasarkan jenis kelamin, umur, dan pendidikan.

\subsubsection{Klasifikasi Responden Berdasarkan Jenis Kelamin}

Tabel 1.3

Klasifikasi Responden Berdasarkan Jenis Kelamin

\begin{tabular}{|l|l|l|l|}
\hline No & $\begin{array}{l}\text { Jenis } \\
\text { Kelamin }\end{array}$ & Jumlah & Presentase \\
\hline 1 & Laki-laki & 24 & $60 \%$ \\
\hline 2 & perempuan & 16 & $40 \%$ \\
\hline \multicolumn{2}{|l}{ Jumlah } & 40 & $100 \%$ \\
\hline
\end{tabular}

Sumber: Data Olah Primer 2017

\subsubsection{Klasifikasi Responden Berdasarkan Umur}

Tabel 1.4

Klasifikasi Responden Berdasarkan Umur

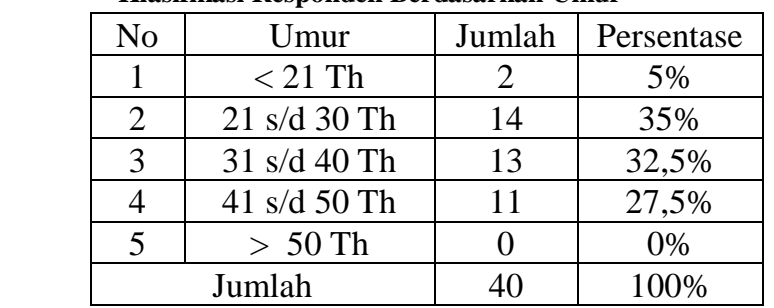

Sumber: Data Olah Primer 2017 


\subsubsection{Klasifikasi Responden Berdasarkan Tingkat Pendidikan}

Tabel 1.5

Klasifikasi Responden Berdasarkan Pendidikan

\begin{tabular}{|c|c|c|c|}
\hline No & Pendidikan & Jumlah & Persentase \\
\hline 1 & SMP & 0 & $0 \%$ \\
\hline 2 & SLTA & 15 & $37,5 \%$ \\
\hline 3 & Diploma III & 9 & $22,5 \%$ \\
\hline 4 & Sarjana/DIV & 16 & $40 \%$ \\
\hline 5 & Magister & 0 & $0 \%$ \\
\hline \multicolumn{2}{|c|}{ Jumlah } & $40 \%$ & $100 \%$ \\
\hline
\end{tabular}

\subsection{Deskriptif Statistik}

Penyebaran kuesioner yang dilakukan pada pengguna aplikasi SISKEUDES terdiri dari konstruk, Data hasil kuesioner yang diperoleh kemudian diolah menggunakan program SPPS 17. Adapun hasil jawaban responden dapat disajikan pada table 1.6 di bawah ini yang meliputi skor rata-rata, skor maksimum, skor minimum, dan simpangan baku. Sumber: Data Primer diolah 2017

Tabel 1.6

Descriptive Statistics

\begin{tabular}{|c|c|c|c|c|c|}
\hline & $\mathbf{N}$ & $\begin{array}{c}\text { Mini } \\
\text { mu } \\
\text { m }\end{array}$ & \begin{tabular}{|c|} 
Max \\
imu \\
m
\end{tabular} & $\begin{array}{c}\text { Mea } \\
\text { n }\end{array}$ & $\begin{array}{c}\text { Std. } \\
\text { Deviation }\end{array}$ \\
\hline $\begin{array}{l}\text { Perceived } \\
\text { Usefulness }\end{array}$ & 40 & 15 & 25 & \begin{tabular}{r|}
18.7 \\
0
\end{tabular} & 2.672 \\
\hline $\begin{array}{l}\text { Perceived } \\
\text { Ease Of } \\
\text { Use }\end{array}$ & 40 & 15 & 30 & $\begin{array}{r}21.5 \\
8\end{array}$ & 3.218 \\
\hline Attitude & 40 & 12 & 20 & $\begin{array}{r}14.0 \\
0\end{array}$ & 1.649 \\
\hline $\begin{array}{l}\text { Behavioral } \\
\text { Intention }\end{array}$ & 40 & 11 & 20 & $\begin{array}{r}14.4 \\
5\end{array}$ & 1.894 \\
\hline Actual Use & 40 & 3 & 7 & 5.50 & .934 \\
\hline $\begin{array}{l}\text { Total } \\
\text { Score }\end{array}$ & 40 & 60 & 96 & $\begin{array}{r}74.2 \\
3\end{array}$ & 7.833 \\
\hline $\begin{array}{l}\text { Valid N } \\
\text { (listwise) }\end{array}$ & 40 & & & & \\
\hline
\end{tabular}

1. Persepsi kegunaan (perceived usefulness) disingkat PU

Konstruk ini terdiri dari 5 butir pernyataan dengan menggunakan 5 skala (5 alternatif jawaban). Dengan nilai rata-rata 18,70 , skor maksimum 25, skor minimum 15, dan simpangan baku 2,672.

2. Persepsi Kemudahan penggunaan (perceived ease of use) disingkat PEOU

Konstruk ini terdiri dari 6 butir penyataan dengan menggunakan 5 skala (5 alternatif jawaban). Dengan nilai rata-rata 21,58 , skor maksimum 30, skor minimum 15, dan simpangan baku 3,218.

3. Persepsi sikap menggunakan teknologi (attitude) disingkat ATT

Konstruk ini terdiri dari 4 butir penyataan dengan menggunakan 5 skala (5 alternatif jawaban). Dengan nilai rata-rata 14,00 skor maksimum 20, skor minimum 12, dan simpangan baku 1,649.

4. Persepsi minat menggunakan teknologi (behavioral intention) disingkat BI

Konstruk ini terdiri dari 4 butir penyataan dengan menggunakan 5 skala (5 alternatif jawaban). Dengan nilai rata-rata 14,45 , skor maksimum 20, skor minimum 11 dan simpangan baku 1,894 .

5. Persepsi penggunaan teknologi sesungguhnya (actual use) disingkat $\mathrm{AU}$

Konstruk ini terdiri dari 2 butir penyataan dengan menggunakan 5 skala (5 alternatif jawaban). Dengan nilai rata-rata 5,50, skor maksimum 7, skor minimum 3 , dan simpangan baku 0,934 .

\subsection{Uji Validitas}

Pada penelitian ini jumlah responden adalah 40 . Berdasarkan distribusi nilai $\mathrm{r}_{\text {tabel }}$ signifikasi 5\% dinyatakan bahwa nilai $r_{\text {tabel }}$ adalah sebesar 0,320 . Dengan demikian jika nilai $r_{\text {hitung }}>r_{\text {tabel }}$ maka jawaban responden dinyatakan valid. Berikut adalah ringkasan hasil uji reabilitas data responden.

Tabel 1.7

Uji Validitas 1

\begin{tabular}{|c|c|c|c|c|}
\hline No & Pernyataan & $\begin{array}{c}\text { Nilai } \\
\text { rhitung }\end{array}$ & $\begin{array}{c}\text { Nilai } \\
\text { rtabel }\end{array}$ & Validitas \\
\hline 1 & PU1 & 0,766 & 0,320 & Valid \\
\hline 2 & PU2 & 0,737 & 0,320 & Valid \\
\hline 3 & PU3 & 0,775 & 0,320 & Valid \\
\hline 4 & PU4 & 0,703 & 0,320 & Valid \\
\hline 5 & PU5 & 0,655 & 0,320 & Valid \\
\hline 6 & PEOU1 & 0,677 & 0,320 & Valid \\
\hline 7 & PEOU2 & 0,696 & 0,320 & Valid \\
\hline 8 & PEOU3 & 0,614 & 0,320 & Valid \\
\hline 9 & PEOU4 & 0,723 & 0,320 & Valid \\
\hline 10 & PEOU5 & 0,651 & 0,320 & Valid \\
\hline 11 & PEOU6 & 0,708 & 0,320 & Valid \\
\hline 12 & ATT1 & 0,681 & 0,320 & Valid \\
\hline 13 & ATT2 & 0,752 & 0,320 & Valid \\
\hline 14 & ATT3 & 0,668 & 0,320 & Valid \\
\hline 15 & ATT4 & 0,075 & 0,320 & Tidak \\
& & & & Valid \\
\hline 16 & BI1 & 0,697 & 0,320 & Valid \\
\hline 17 & BI2 & 0,702 & 0,320 & Valid \\
\hline 18 & BI3 & 0,505 & 0,320 & Valid \\
\hline 19 & BI4 & 0,446 & 0,320 & Valid \\
\hline 20 & AU1 & 0,247 & 0,320 & Tidak \\
& & & & Valid \\
\hline 21 & AU2 & 0,337 & 0,320 & Valid \\
\hline Sul
\end{tabular}

Sumber: Data primer diolah, 2017 
Berdasarkan hasil uji validitas di atas ternyata ada ada 2 buah pernyataan yang tidak valid. Dengan demikian dilakukan revisi, 2 (dua) buah pertanyaan tersebut dibuang. Berikut ini adalah hasil uji validitas setelah revisi:

Tabel 1.8

Uji Validitas 2

\begin{tabular}{|c|c|c|c|c|}
\hline No & Pernyataan & $\begin{array}{c}\text { Nilai } \\
\mathrm{r}_{\text {hitung }}\end{array}$ & $\begin{array}{c}\text { Nilai } \\
\text { rtabel }\end{array}$ & Validitas \\
\hline 1 & PU1 & 0,766 & 0,320 & Valid \\
\hline 2 & PU2 & 0,737 & 0,320 & Valid \\
\hline 3 & PU3 & 0,775 & 0,320 & Valid \\
\hline 4 & PU4 & 0,703 & 0,320 & Valid \\
\hline 5 & PU5 & 0,655 & 0,320 & Valid \\
\hline 6 & PEOU1 & 0,677 & 0,320 & Valid \\
\hline 7 & PEOU2 & 0,696 & 0,320 & Valid \\
\hline 8 & PEOU3 & 0,614 & 0,320 & Valid \\
\hline 9 & PEOU4 & 0,723 & 0,320 & Valid \\
\hline 10 & PEOU5 & 0,651 & 0,320 & Valid \\
\hline 11 & PEOU6 & 0,708 & 0,320 & Valid \\
\hline 12 & ATT1 & 0,681 & 0,320 & Valid \\
\hline 13 & ATT2 & 0,752 & 0,320 & Valid \\
\hline 14 & ATT3 & 0,668 & 0,320 & Valid \\
\hline 15 & BI1 & 0,697 & 0,320 & Valid \\
\hline 16 & BI2 & 0,702 & 0,320 & Valid \\
\hline 17 & BI3 & 0,505 & 0,320 & Valid \\
\hline 18 & BI4 & 0,446 & 0,320 & Valid \\
\hline 19 & AU2 & 0,337 & 0,320 & Valid \\
\hline \multicolumn{5}{|c|}{ Sumber: Data Olah Primer, 2017 } \\
\end{tabular}

Setelah direvisi maka butir pernyataan pada kuesioner yang valid sebanyak 19 butir penyataan. Jadi hasil dari dari 19 butir tersebut yang diolah oleh peneliti.

\subsection{Uji Reliabilitas}

Pengujian reliabilitas pada penelitain ini menggunakan metode alpha cronbanch. Konstruk dinyatakan realibel jika nilai cronbach alpha di atas 0,70. Output cronbach alpha dapat dilihat pada table berikut ini:

Tabel 1.9

Reliability Statistics

\begin{tabular}{|r|r|}
\hline Cronbach's Alpha & N of Items \\
\hline .779 & \\
& \\
\hline
\end{tabular}

Sumber: Data Olah Primer 2017

Berdasarkan data dari tabel di atas dapat dilihat bahwa rata-rata nilai Cronbach Alpha di atas 0,70 yaitu sebesar 0,79 maka dapat disimpulkan bahwa konstruk penelitian reliabel.

\subsection{Uji Normalitas}

Berikut ini ada hasil uji normalitas data dengan menggunakan program SPPS 17.

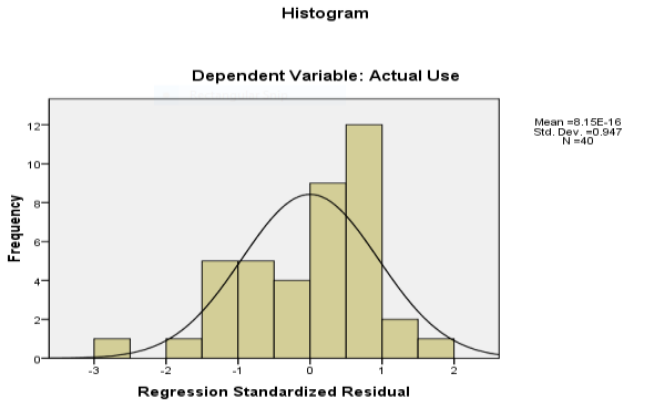

Gambar 2.3

Grafik Histogram Uji Normalitas

$$
\begin{aligned}
& \text { Normal P.P Plot of Regression Standardized } \\
& \text { Residual }
\end{aligned}
$$

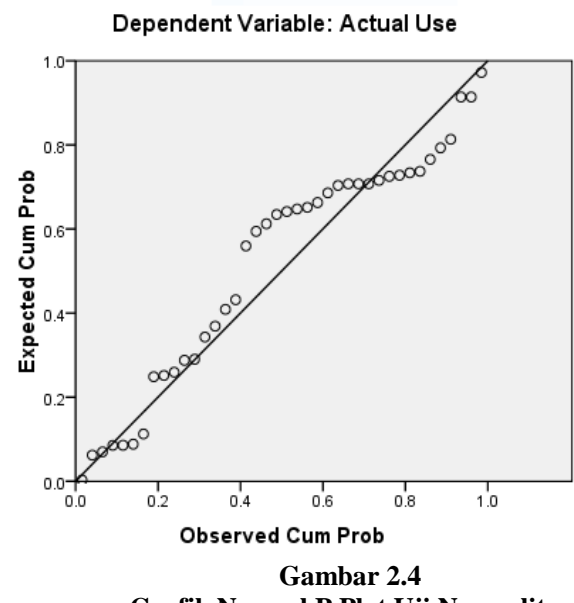

Berdasarkan gambar 2.3 dan 2.4 dapat diketahui bahwa data yang digunakan dalam penelitian ini adalah data yang mempunyai distribusi normal karena pada pada grafiknya histogramnya membentuk lonceng, dan pada grafik $\mathrm{P}$ Plot grafiknya lurus.

\subsection{Analisis Regresi Linear Berganda}

Peneliti akan melakukan pengujian hipotesis dengan menggunakan teknik analisis regresi linear berganda yang perhitungannya menggunakan program SPPS 17. Teknis analisis regresi linear berganda ini dapat digunakan untuk mengetahui seberapa besar pengaruh dari variabel independen terhadap variabel dependen.

Berikut ini adalah hasil analisis regresi linear berganda tujuh hipotesis dengan program SPSS 17. 
Tabel 1.10 Hasil Uji Hipotesis

\begin{tabular}{|l|l|c|}
\hline \multicolumn{1}{|c|}{ Hipotesis } & $\begin{array}{c}\text { Nilai } \\
\text { Signifik } \\
\text { ansi }\end{array}$ & $\begin{array}{c}\text { Pengaruh/tidak } \\
\text { pengaruh }\end{array}$ \\
\hline $\begin{array}{l}\text { Hipotesis 1: } \\
\text { PEOU terhadap } \\
\text { PU }\end{array}$ & 0,002 & Berpengaruh \\
\hline $\begin{array}{l}\text { Hipotesis 2: } \\
\text { PEOU terhadap } \\
\text { ATT }\end{array}$ & 0,001 & Berpengaruh \\
\hline $\begin{array}{l}\text { Hipotesis 3: PU } \\
\text { terhadap ATT }\end{array}$ & 0,000 & Berpengaruh \\
\hline $\begin{array}{l}\text { Hipotesis 4: } \\
\text { ATT terhadap } \\
\text { BI }\end{array}$ & 0,599 & Tidak Berpengaruh \\
\hline $\begin{array}{l}\text { Hipotesis 5:PU } \\
\text { terhadap BI }\end{array}$ & 0,009 & Berpengaruh \\
\hline $\begin{array}{l}\text { Hipotesis 6 : BI } \\
\text { terhadap AU }\end{array}$ & 0,865 & Tidak Berpengaruh \\
\hline $\begin{array}{l}\text { Hipotesis 7: PU } \\
\text { terhadap AU }\end{array}$ & 0,700 & Tidak Berpengaruh \\
\hline \multicolumn{2}{|l|}{ Sumber: Data Olah Primer 2017 } \\
\hline
\end{tabular}

Berdasarkan tabel 1.10 dapat diketahui bahwa hipotesis yang diterima dalam penelitian ini adalah hipotesis 1, 2, 3 dan 5. Hal ini dapat dilihat dari adanya pengaruh antar variabel yang sudah dijelaskan pada pembahasan antar konstruk. Hipotesis yang tidak berpengaruh bukan berarti tidak berpengaruh sepenuhnya, namun tidak berpengaruh secara signifikan atau positif.

\section{SIMPULAN}

\subsection{Simpulan}

1. Persepsi kemudahan penggunaan (perceived ease of use) berpengaruh positif dan signifikan terhadap persepsi kegunaan (perceived usefulness), karena nilai signifikansinya $>0,05$ yaitu sebesar 0,002. Artinya semakin mudah teknologi aplikasi Siskeudes dioperasikan, maka teknologi aplikasi tersebut akan banyak digunakan oleh pengguna yang bersangkutan. Hasil dari penelitian ini didukung oleh penelitian sebelumnya yaitu hasil penelitian yang dilakukan oleh Wahyuni (2014), dimana konstruk perceived ease of use berpengaruh positif dan signifikan terhadap perceived usefulness.

2. Persepsi Kemudahan penggunaan persepsian (perceived ease of use) berpengaruh positif dan signifikan tehadap sikap menggunakan teknologi (attitude toward using), karena nilai signifikansinya $<0,05$ yaitu sebesar 0.001 . Semakin mudah aplikasi SISKEUDES dioperasikan maka tidak akan mempengaruhi sikap penggunanya. Hasil dari penelitian ini didukung oleh penelitian sebelumnya yaitu hasil penelitian yang dilakukan oleh Ardhiani (2015), dimana konstruk perceived ease of use tidak berpengaruh positif dan signifikan terhadap attitude toward using.

3. Kegunaan persepsian (perceived usefulness) berpengaruh positif dan signifikan terhadap sikap menggunakan teknologi (attitude toward using technology), karena nilai signifikansinya < 0,05 yaitu sebesar 0,000. Artinya sikap seseorang akan mempengaruhi minatnya untuk menggunakan aplikasi SISKEUDES. Hasil penelitian ini didukung oleh penelitian sebelunya yang dilakukan oleh Loggar Bhilawa pada tahun 2010 tentang analisis penerimaan Mobile Banking (M-Banking) dengan pengalaman (experience) sebagai variabel eksternal dengan menggunakan pendekatan technology acceptance model (TAM).

4. Sikap menggunakan teknologi (attitude toward using technology) tidak berpengaruh terhadap minat menggunakan teknologi (behavioral intention) ATT tidak berpengaruh terhadap variabel terhadap variabel BI karena nilai signifikansinya $>0,05$ yaitu 0,599 . Hasil dari penelitian ini didukung oleh penelitian sebelumnya yaitu hasil penelitian yang dilakukan oleh Arief (2014), dimana konstruk attitude toward using technology tidak berpengaruh positif dan signifikan terhadap behavioral intention.

5. Kegunaan persepsian (perceived usefulness) berpengaruh positif dan signifikan terhadap minat menggunakan teknologi (behavioral intention), karena nilai signifikansinya $<0,05$ yaitu sebesar 0,009. Artinya semakin banyak kegunaan aplikasi SISKEUDES, maka semakin banyak orang yang akan menggunakannya. Hasil dari penelitian ini didukung oleh penelitian sebelumnya yaitu hasil penelitian yang dilakukan oleh Gunawan et.al (2016), dimana konstruk perceived usefulness berpengaruh positif dan signifikan terhadap behavioral intention..

6. Minat perilaku (behavioral intention) tidak berpengaruh positif dan signifikan terhadap penggunaan teknologi sesungguhnya (actual technology use), karena nilai signifikansinya $>0,05$ yaitu sebesar 0, 865. Artinya minat seseorang tidak mempengaruhi seberapa sering atau seberapa berat pengguna dalam menggunakan aplikasi SISKEUDES. Hasil dari penelitian ini didukung oleh penelitian sebelumnya yaitu hasil penelitian yang dilakukan oleh Wahyuni (2014) dengan judul analisis penerimaan teknologi informasi SIAKD pada pemerintah kabupaten Enrekang provinsi Kalimantan Selatan, dimana konstruk behavioral intention tidak berpengaruh positif dan signifikan terhadap actual technology use. 
7. Kegunaan persepsian (perceived usefulness) tidak berpengaruh positif dan signifikan terhadap penggunaan teknologi sesungguhnya baik secara langsung, tidak langsung/melalui kolerasi dengan variabel BI, dan secara total terhadap penggunaan teknologi sesungguhnya (actual technology use), karena nilai signifikansinya >0,05 yaitu sebesar 0, 700 . Artinya penggunaan aplikasi SISKEUDES sesungguhnya tidak dipengaruhi oleh kegunaan persepsinya. Hasil dari penelitian ini didukung oleh penelitian sebelumnya yaitu hasil penelitian yang dilakukan oleh Wahyuni (2014) dengan judul analisis penerimaan teknologi informasi SIAKD ditinjau dari persepsi pemakainya pada Pemkab Enrekang Prov. Kalsel, dimana konstruk perceived usefulness tidak

\section{DAFTAR PUSTAKA}

[1] [1] Budianas, N. (2013). Uji Asumsi Klasik. [Online]. Tersedia: http://nanangbudianas.blogspot.in/2013/02/u ji-asumsi-klasik.html.

[2] Instruksi Presiden Republik Indonesia Nomor 3 Tahun 2003 Tentang Kebijakan dan Strategi Nasional Pengembangan $E$ Government.

[3] [3]Jogiyanto, (2007). Sistem Informasi Keperilakuan. Yogyakarta: Percetakan ANDI OFFSET.

[4] Kharisma, M (2010). Sistem Informasi Keuangan Finansial. [Online].

[5] https://mutiarakharisma.wordpress.com/siste m-informasi-keuangan-financialinformation-system/

[6] Kuncoro, M. (2009). Metode Riset untuk Bisnis dan Ekonomi. Jakarta: Erlangga.

[7] Permendagri Nomor 113 Tentang Pedoman Pengelolaan Keuangan Daerah.

[8] Sarwono, J. (2011). Mengenal Path Analysis: Sejarah, Pengertian dan Aplikasi. berpengaruh positif dan signifikan terhadap actual technology use.

\subsection{Saran}

Beberapa saran dari penelitian ini adalah:

1. Pengujian hanya dilakukan dengan konstruk murni, sebaiknya di masa yang akan datang peneliti selanjutnya menambahkan konstruk atau variable tambahan yang di sarankan dalam teori TAM.

2. Analisis penerimaan teknologi aplikasi sebaiknya dilakukan pada aplikasi aplikasi yang lain, agar pihak terkait khususnya pemerintah dapat melihat penyebaran dan penerimaan aplikasi di lingkungan kerjanya, sebagai ukuran untuk penggunaan aplikasi di masa yang akan datang.

Jurnal Ilmiah Manajemen Bisnis. Vol 11, No. 2 November 285-296.

[9] Setyadharma, A. (2010). Uji Asumsi Klasik. Disertasi. Semarang: Fakultas Ekonomi Universitas Negeri Semarang.

[10] Sugiyono, (2012). Metode Penelitian Pendidikan-Pendekatan Kuantitatif, Kualitatif, R \& D. Badung: Alfabeta Bandung.

[11] Undang-Undang Nomor 17 Tahun 2003 Tentang Keuangan Negara.

[12] Undang-Undang Nomor 25 Tahun 2004 Sistem Perencanaan Pembangunan Nasional.

[13] Undang-Undang Nomor 6 Tahun 2014 Tentang Desa.

[14] Wahana Komputer, (2010). Mengolah Data Statistik Hasil Penelitian Dengan SPPS 17. Yogyakarta: Percetakan Andi Offset.

[15] Wahyuni, Idra (2014). "Analisis Penerimaan Sistem Teknologi Informasi SIAKD ditinjau dari Persepsi Pemakainya pada pemerintah Kabupaten Enrekang Provinsi Sulawesi Selatan. Tesis. Makassar: Fakultas Ekonomi Dan Bisnis Universitas Hasanudin Makassar 